\title{
Effects of dexmedetomidine on porcine pulmonary artery vascular smooth muscle
}

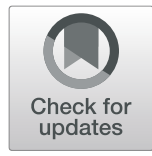

Mami Chikuda and Kenichi Sato ${ }^{*}$ (1)

\begin{abstract}
Background: The $a_{2}$-receptor agonist dexmedetomidine (Dex) has been shown to produce sedative and analgesic effects not only with systemic administration but also when administered in the extradural space and around peripheral nerves. The effects and mechanism of action of Dex on pulmonary arteries, however, have not been determined. This study therefore aimed to investigate the effect of Dex on pulmonary arterial vascular smooth muscle by evaluating changes in isometric contraction tension. We then attempted to determine the effects of Dex on depolarization stimulation and receptor stimulation.

Methods: Endothelium-denuded porcine pulmonary arteries were sliced into 2- to 3-mm rings. We then exposed them to certain substances at various concentrations under different conditions of baseline stimulation (with $\mathrm{KCl}$, adrenaline, caffeine, or histamine) and to $\mathrm{a}_{2}$-receptor stimulants or antagonists, or $\mathrm{a}_{1}$-receptor antagonists (imidazoline, yohimbine, rauwolscine, prazosin), and different conditions of $\mathrm{Ca}^{2+}$ depletion of the intracellular reservoir or extracellular stores. We measured the changes in isometric contraction tension with each addition or change in conditions.

Results: Dex enhanced the contraction induced by high-concentration $\mathrm{KCl}$ stimulation. Dex-induced enhancement of contraction induced by high-concentration $\mathrm{KCl}$ was completely suppressed by yohimbine and rauwolscine, which are $a_{2}$-receptor antagonists, but not by prazosin. Dex, imidazoline, yohimbine, and rauwolscine reduced the increases in contraction tension induced by the receptor stimulant adrenaline. Dex suppressed the adrenaline-induced increases in contraction tension after depletion of the $\mathrm{Ca}^{2+}$ reservoir. In the absence of extracellular $\mathrm{Ca}^{2+}$, Dex suppressed the adrenaline- and histamine-induced increases in contraction tension but did not affect caffeineinduced increases.

Conclusions: Dex-enhanced, high-concentration $\mathrm{KCl}$-induced contraction was mediated by $\mathrm{a}_{2}$-receptors. Adrenaline-induced contraction was suppressed by the $a_{2}$-receptor stimulant Dex and $a_{2}$-receptor antagonists yohimbine and rauwolscine, suggesting that the effect of Dex on adrenaline-induced contraction is attributable to its $\mathrm{a}_{2}$-receptor-blocking action. Dex inhibited receptor-activated $\mathrm{Ca}^{2+}$ channels and phosphatidylinositol-1,4,5triphosphate-induced $\mathrm{Ca}^{2+}$ release but not $\mathrm{Ca}^{2+}$-induced $\mathrm{Ca}^{2+}$ release.
\end{abstract}

Keywords: Porcine pulmonary artery, Dexmedetomidine, Adrenaline, Isometric tension

\section{Background}

The $\alpha_{2}$-receptor agonists have been shown to produce sedative and analgesic effects not only with systemic administration but also when administered in the extradural space and around peripheral nerves [1-3]. Among the $\alpha_{2}$-receptor agonists, dexmedetomidine hydrochloride (Dex) is added to local anesthetics to increase their potency and extend their duration of action.

\footnotetext{
* Correspondence: satoken@iwate-med.ac.jp

Division of Dental Anesthesiology, Department of Reconstructive Oral and Maxillofacial Surgery, School of Dentistry, Iwate Medical University, 1-3-27 Chuo-dori, Morioka, Iwate 020-8505, Japan
}

For example, administration of Dex $0.5 \mu \mathrm{g} / \mathrm{kg}$ with $0.5 \%$ lidocaine to the brachial plexus for brachial nerve block significantly extends the duration of the local anesthetic's effect [2] and provides postoperative analgesia with a single administration. In dentistry, the current use of local anesthetics containing adrenaline may cause abnormal blood pressure increases, leading to adverse effects such as cerebrovascular disease. To prevent these complications, the adrenaline in local anesthetics should be replaced with an additive that causes smaller fluctuations in the circulation during local anesthesia [4-6]. The use of

(c) The Author(s). 2019 Open Access This article is distributed under the terms of the Creative Commons Attribution 4.0 International License (http://creativecommons.org/licenses/by/4.0/), which permits unrestricted use, distribution, and 
Dex-containing lidocaine as a local anesthetic may offer simultaneous prolongation and potentiation of anesthetic effects and may be useful for dental treatment in patients with cardiovascular disease. Dex has thus attracted attention and is being tested in clinical studies as an additive agent for dental local anesthesia. The effects and mechanism of action of Dex on the cardiopulmonary vascular system should therefore be clarified. Although several in vivo studies have shown the effects of Dex on aortic or coronary arteries in various animals, there are few reports regarding its effect on other peripheral vessels. The pulmonary artery has been relatively unexplored, even though it is a prominent artery that nourishes the lungs. Pulmonary vasoconstriction, with its resultant progressive elevation of pulmonary arterial resistance and pressure, plays a central role in pulmonary arterial hypertension, which could be fatal $[7,8]$. Nevertheless, there are only a few reports of the effects of Dex on the pulmonary artery. The diversity of effects of Dex on smooth muscle precludes guessing its effects on any individual smooth muscle.

To elucidate the effects and mechanism of action of Dex on vascular smooth muscle of the pulmonary artery, we measured isometric contraction tension in the artery. We then attempted to determine the effects of Dex on depolarization stimulation and receptor stimulation. To evaluate Dex's possible mechanisms of action, we investigated components of the two most important pathways involved in intracellular $\mathrm{Ca}^{2+}$ fluctuations during vascular smooth muscle contractioni.e., intracellular influx of extracellular $\mathrm{Ca}^{2+}$ and release of stored intracellular $\mathrm{Ca}^{2+}$ within the cell.

\section{Methods}

This study was approved by the Institutional Review Committee on the Ethics of Animal Experiments of Iwate Medical University. All experiments were conducted in accordance with the Institutional Animal Care and Use Committee guidelines (Ethical number 26-010).

\section{Reagents and solutions}

All chemicals were obtained from Wako Pure Chemical Industries (Osaka, Japan).

In all experiments, air-equilibrated Hank's balanced salt solution (HBSS) was used to maintain the arteries under the resting condition. HBSS was composed of 137 $\mathrm{mM} \mathrm{NaCl}, 5.4 \mathrm{mM} \mathrm{KCl}, 0.8 \mathrm{mM} \quad \mathrm{MgSO}_{4}, 1.26 \mathrm{mM}$ $\mathrm{CaCl}_{2}, 0.34 \mathrm{mM} \mathrm{Na} \mathrm{HPO}_{4}, 0.44 \mathrm{mM} \mathrm{KH_{2 }} \mathrm{PO}_{4}, 4.2 \mathrm{mM}$ $\mathrm{NaHCO}_{3}$, and $5.55 \mathrm{mM}$ glucose (pH 7.34). All other salt solutions used as perfusates were prepared by modifying the HBSS. Isotonic $60 \mathrm{mM} \mathrm{KCl}$ solution was prepared by replacing the $\mathrm{NaCl}$ in the HBSS solution with an equimolar amount of $\mathrm{KCl}$.

\section{Arterial ring preparation and isometric tension measurement}

The pigs were killed as part of a routine procedure in the slaughterhouse where we obtained the porcine lungs. The one-third of the pulmonary arteries that were $2-3 \mathrm{~mm}$ in diameter were excised from the lung of a 6-month-old slaughtered pig and cut into rings 2$3 \mathrm{~mm}$ in length. The endothelium, which was rubbed gently against the thin arm of stainless steel tweezers $[8,9]$, was then denuded and the rings inverted (inner surface facing outward) to prepare specimens of pulmonary arterial vascular smooth muscle. It was confirmed that $3 \mu \mathrm{M}$ acetylcholine induced relaxation of the arterial rings, which disappeared after this procedure. The arterial rings were maintained in HBSS at $5{ }^{\circ} \mathrm{C}$ until used for the assessments.

Specimens were placed in a perfusion chamber (with $3 \mathrm{ml}$ of perfusate), and a resting tension of $4-7 \mathrm{mN}$ was applied. The perfusate, adjusted to $37^{\circ} \mathrm{C}$, flowed at a rate of $1.6 \mathrm{ml} / \mathrm{min}$ controlled by a peristaltic pump (SMP-23; Tokyo Rikakikai Co., Fujisawa, Japan). After perfusion with HBSS for $30 \mathrm{~min}$, various stimulants were administered, and the resulting contraction tension after each addition was measured via the following steps. The end of the specimen in the perfusion chamber was fixed to a manipulator (M-152; Narishige, Tokyo, Japan) and the other end to a tension transducer (UL-2GR; Minebea, Tokyo, Japan) using a tungsten wire. Data were recorded on PowerLab ${ }^{\circ}$ (ADInstruments, Bella Vista, Australia) via a pressure amplification unit (N4438; NEC San-ei, Tokyo, Japan).

The experiments were undertaken, as follows.

1. At the beginning of each experiment, after approximately 2 min of perfusion with $60 \mathrm{mM} \mathrm{KCl}$ solution (Figs. 1, 2, 4, 6 and 7) or $5 \mu \mathrm{M}$ adrenaline (Fig. 5), the contraction tension was measured, recorded, and used as the control value for that experiment.

2. The concentration-response relations for Dex and imidazoline were determined by adding each to HBSS or $60 \mathrm{mM} \mathrm{KCl}$ (Figs. 1 and 2). The contraction tension measured in $60 \mathrm{mM} \mathrm{KCl}$ at the beginning of the experiment was used as the control value. The concentration-response relations for Dex, imidazoline, yohimbine, and rauwolscine were determined by adding each to $5 \mu \mathrm{M}$ adrenaline (Fig. 5) for $2 \mathrm{~min}$ and then monitoring the reaction for almost $20 \mathrm{~min}$. The contraction tension measured in $5 \mu \mathrm{M}$ of adrenaline at the beginning of the experiment was used as the control value.

3. After recording the amplitude of the control contraction induced by $\mathrm{KCl}, 5 \mu \mathrm{M}$ Dex was added to $60 \mathrm{mM} \mathrm{KCl}$ and the response recorded. Then, 


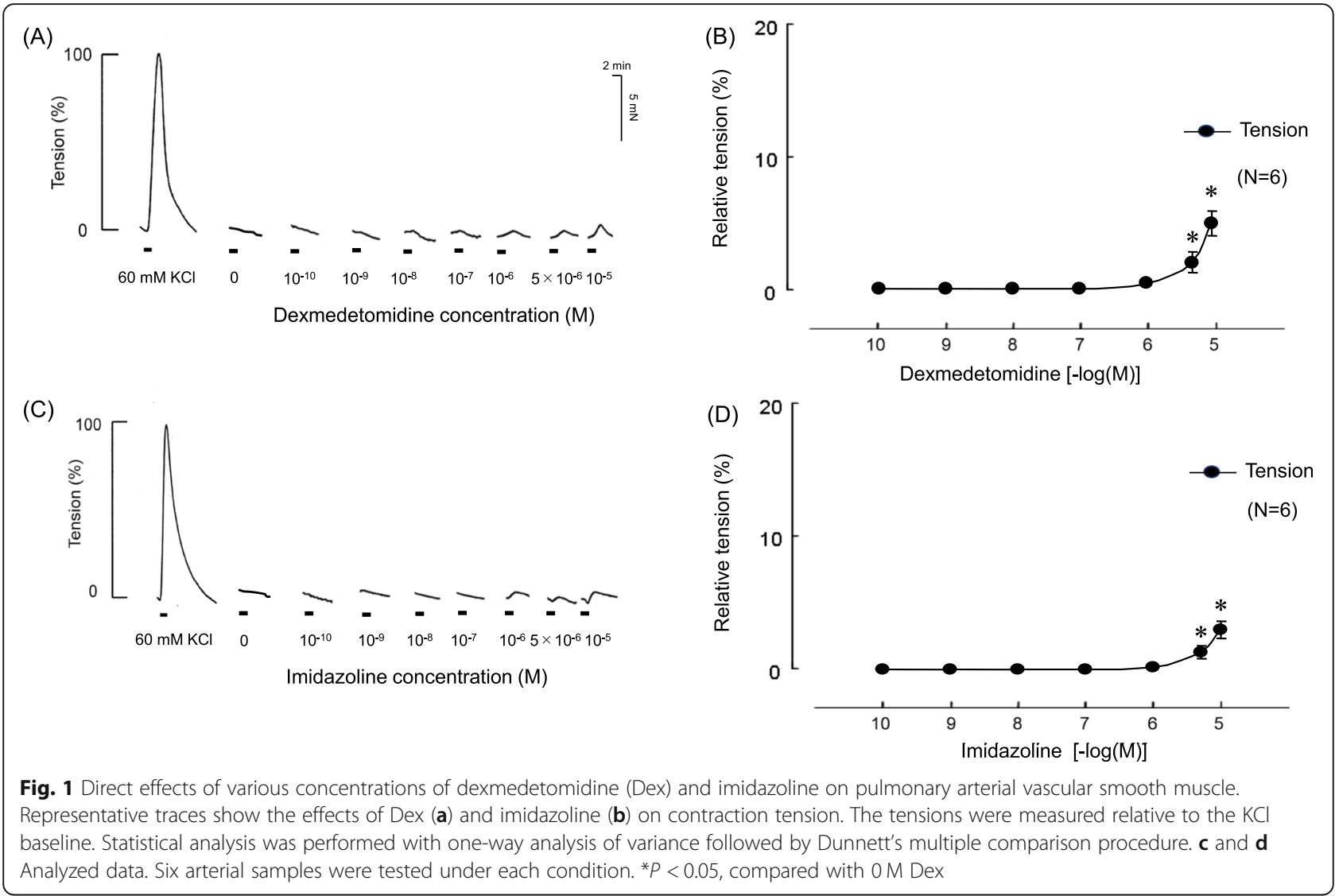

$1 \mu \mathrm{M}$ of yohinbine, rauwolscine, and prazosin each were added to $60 \mathrm{mM} \mathrm{KCl}$ containing $5 \mu \mathrm{M}$ Dex

(Fig. 4) for 2 min and then monitored for almost 20 min to determine the responses. The contraction tension measured in $60 \mathrm{mM} \mathrm{KCl}$ at the beginning of the experiment was used as the control value.

4. After depleting the intracellular $\mathrm{Ca}^{2+}, 5 \mu \mathrm{M}$ Dex was added to $5 \mu \mathrm{M}$ adrenaline and the response recorded (Fig. 6). The contraction tension measured in $60 \mathrm{mM} \mathrm{KCl}$ at the beginning of the experiment was used as the control value.

5. After depletion of extracellular $\mathrm{Ca}^{2+}$, the effect of $5 \mu \mathrm{M}$ Dex in $\mathrm{Ca}^{2+}$-free HBBS, was determined by adding $5 \mu \mathrm{M}$ Dex to $5 \mu \mathrm{M}$ adrenaline, $5 \mu \mathrm{M}$ histamine, and $25 \mathrm{mM}$ caffeine, respectively, for 2 min (Fig. 7). Each solution was then monitored for almost 20 min to determine the responses. The contraction tension measured in $60 \mathrm{mM} \mathrm{KCl}$ at the beginning of the experiment was used as the control value.

The preliminary experiments showed that, after application of each of these substances, an almost 20-min interval was sufficient for the tension to return to the control level (Figs. 1, 2, 4, 5, 6 and 7). For all experiments, each new set of ingredients was carried out with fresh preparations because it has been suggested that down-regulation of $\alpha_{2}$-adenoreceptors often occurs after prolonged $\alpha_{2}$-agonist treatment $[10,11]$.

\section{Statistical analysis}

Values are presented as means \pm SEM. Statistical analysis was performed using SPSS for Windows 10 (IBM SPSS Statistics 26; IBM Corp., Armonk, NY, USA). Differences between the means of two groups were evaluated using Student's t test. Differences among multiple groups were evaluated with one-way analysis of variance followed by Dunnett's or Scheffe's multiple comparison procedure. Differences were considered significant at $p<0.05$.

\section{Results}

Direct effects of various concentrations of Dex and imidazoline on pulmonary arterial vascular smooth muscle

Significant changes in contraction tension were observed with the addition of Dex and imidazoline at concentrations of $\geq 5 \mu \mathrm{M}$ (Fig. 1).

Effects of various concentrations of Dex and imidazoline on high-concentration $\mathrm{KCl}$-induced contraction tension Dex enhanced the contraction induced by high $\mathrm{KCl}$ stimulation, with the increases reaching significance at 


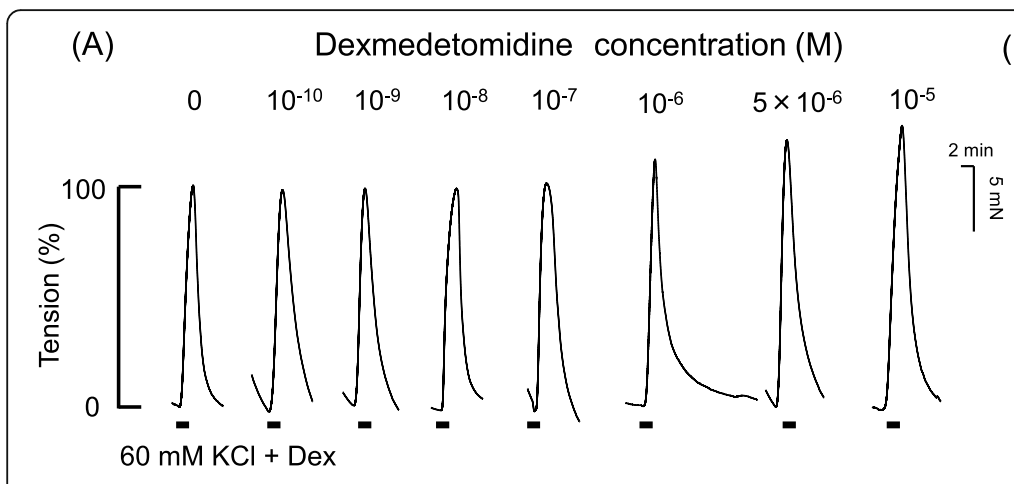

(B)

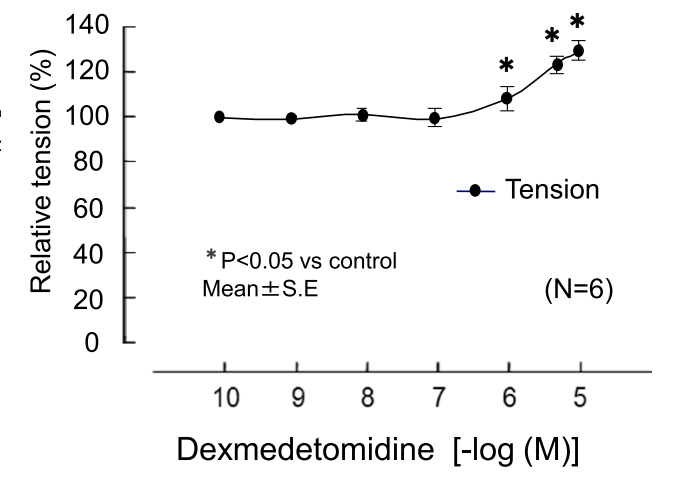

(C)

Imidazoline concentration (M)

(D)
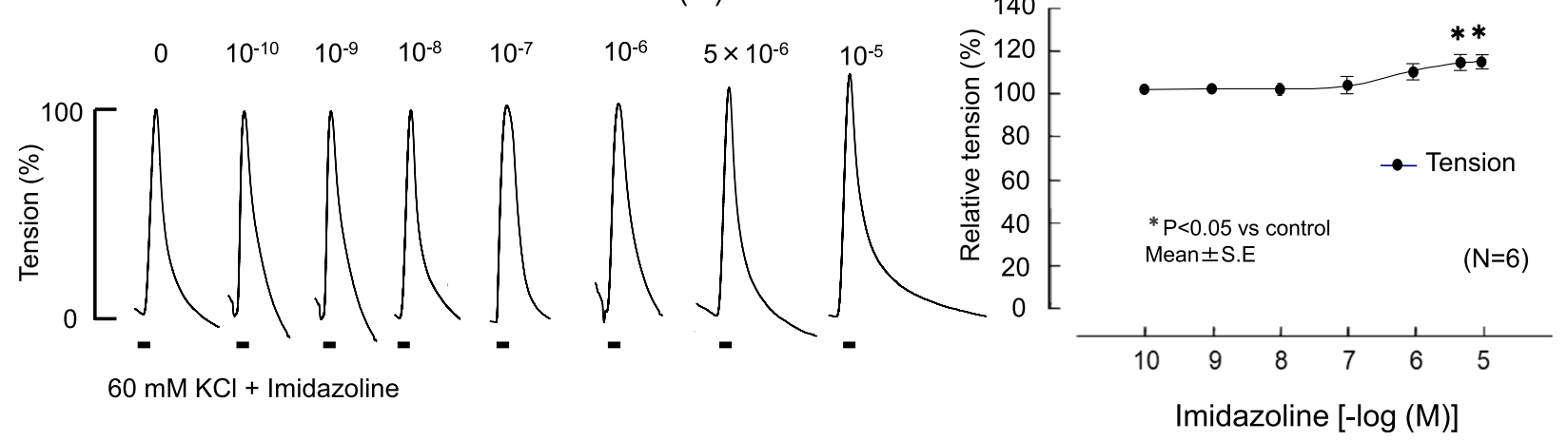

Fig. 2 Effects of dexmedetomidine and imidazoline on contraction tension with $60 \mathrm{mM} \mathrm{KCl}$. Representative traces show the effects of dexmedetomidine and imidazoline on contraction tension in endothelium-denuded porcine pulmonary artery $(\mathbf{a}, \mathbf{c})$ induced with $60 \mathrm{mM} \mathrm{KCl}$. $\mathbf{b}$ and $\mathbf{d}$ Analyzed data. The contraction tensions were normalized to $60 \mathrm{mM} \mathrm{KCl}$ in each set and expressed as a relative value (in percents). The tensions were measured relative to the $\mathrm{KCl}$ baseline. Statistical analysis was performed with one-way analysis of variance followed by Dunnett's multiple comparison procedure. Each bar and accompanying line indicate the mean and SE of the group. Six samples were included in each group. ${ }^{*} P<0.05$, compared with $60 \mathrm{mM} \mathrm{KCl}$

Dex concentrations of $\geq 1 \mu \mathrm{M}$ and imidazoline concentrations of $\geq 5 \mu \mathrm{M}$ (Fig. 2).

\section{Comparison between the percentages of changes in} direct effects of Dex or imidazoline on pulmonary arterial vascular smooth muscle and that of changes in effects of Dex or imidazoline on contraction tension induced with $60 \mathrm{mM} \mathrm{KCl}$

There were significant differences between the amount of changes in direct effects of Dex and imidazoline on pulmonary arterial vascular smooth muscle and that of changes in effects on contraction tension induced with $60 \mathrm{mM} \mathrm{KCl} \mathrm{(Fig.} \mathrm{3).}$

Effects of yohimbine, rauwolscine, and prazosin on highconcentration $\mathrm{KCl}$-induced contraction tension

Yohimbine, rauwolscine, and prazosin had no significant effect on $60 \mathrm{mM} \mathrm{KCl-induced} \mathrm{contraction} \mathrm{tension} \mathrm{in}$ pulmonary arterial vascular smooth muscle. Increases in contraction tension by stimulation with $60 \mathrm{mM} \mathrm{KCl}$ containing Dex were significantly suppressed by yohimbine and rauwolscine, which are $\alpha_{2}$-receptor antagonists, although there was no significant difference observed with prazocin, an $\alpha_{1}$-receptor antagonist (Fig. 4).

\section{Effects of various concentrations of Dex, imidazoline, yohimbine, and rauwolscine on adrenaline-induced contraction tension}

Dex, imidazoline, yohimbine, and rauwolscine each decreased adrenaline-induced increases in contraction tension in a concentration-dependent manner in pulmonary arterial vascular smooth muscle (Fig. 5). The 50\% inhibitory concentrations were $2.083 \mu \mathrm{M}$ for Dex, $0.8996 \mu \mathrm{M}$ for imidazoline, $0.376 \mu \mathrm{M}$ for yohimbine, and $0.5702 \mu \mathrm{M}$ for rauwolscine.

Effects of Dex on adrenaline-induced contraction tension with $\mathrm{Ca}^{2+}$ reservoir depletion

The first administration of caffeine, which caused the intracellular reservoir to release $\mathrm{Ca}^{2+}$ during perfusion 

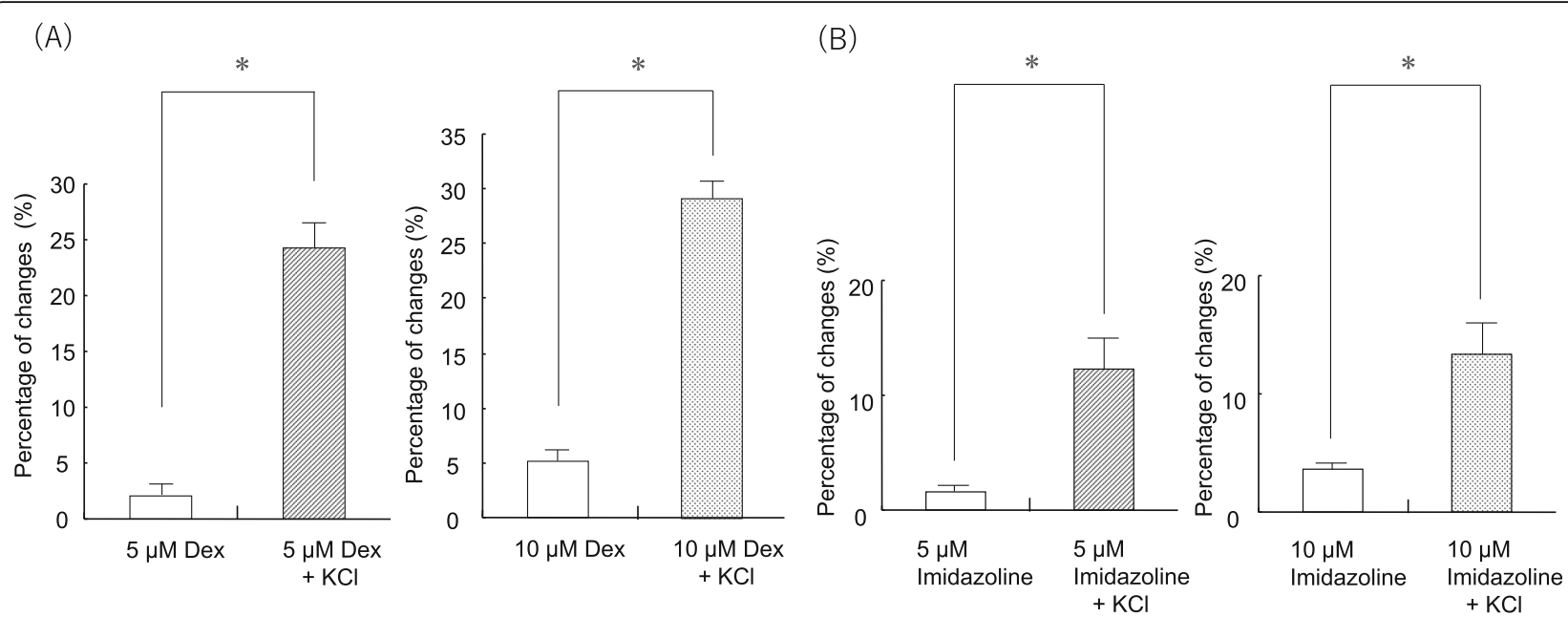

Fig. 3 Comparison between the percent changes in direct effects of dexmedetomidine (Dex) on pulmonary arterial vascular smooth muscle (Fig. 1) and that of changes in the effects of Dex on contraction tension induced with $60 \mathrm{mM} \mathrm{KCl}$ (Fig. 2). The percent change in Dex on contraction tension induced with $60 \mathrm{mM} \mathrm{KCl}$ was measured relative to the contraction tension baseline induced with $\mathrm{KCl}$. Each bar and accompanying line indicate the mean and SE of a group. Statistical analysis was performed with Student's $t$ test. ${ }^{*} P<0.05$, compared with the percent changes in direct effects of Dex

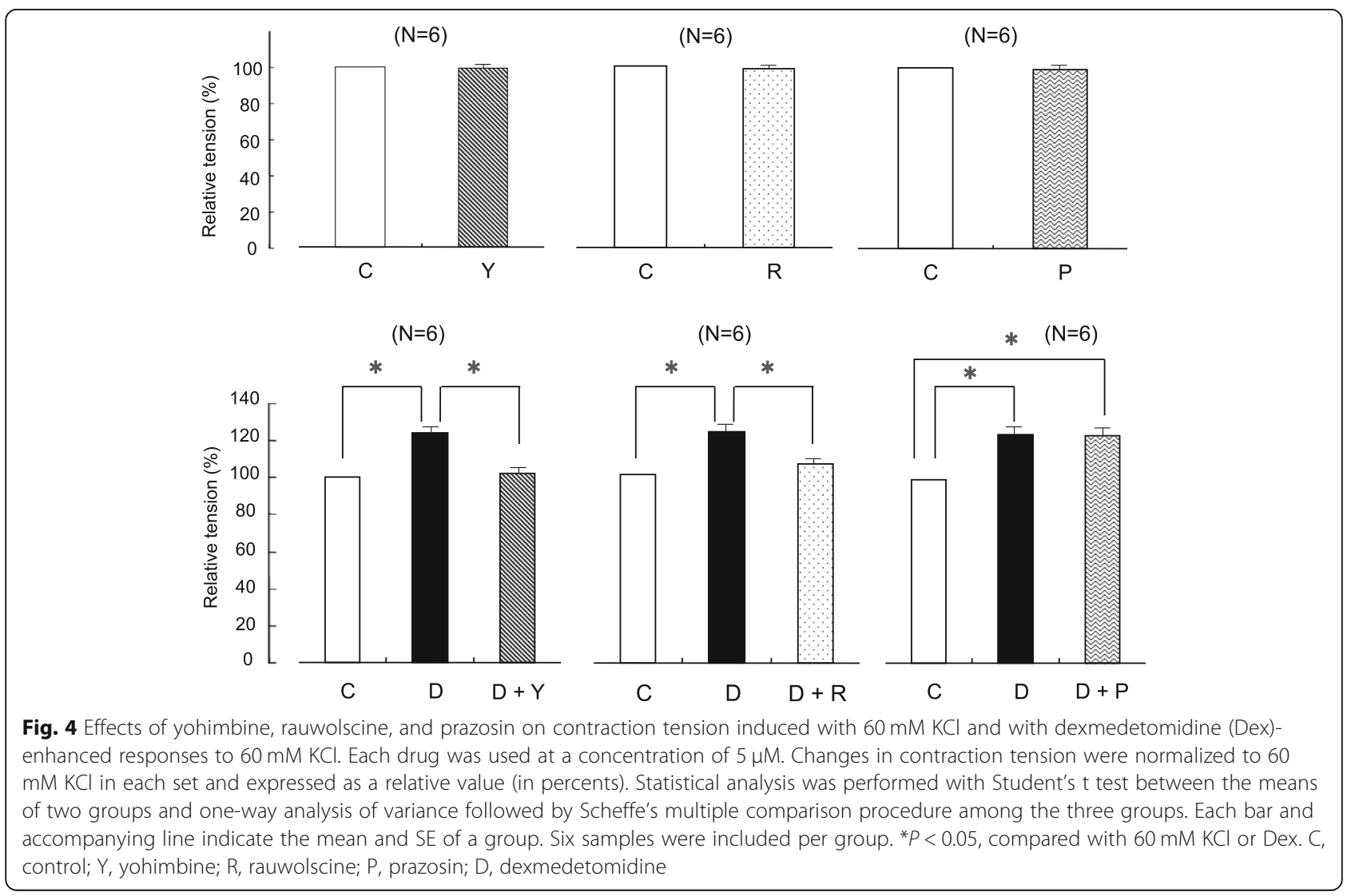




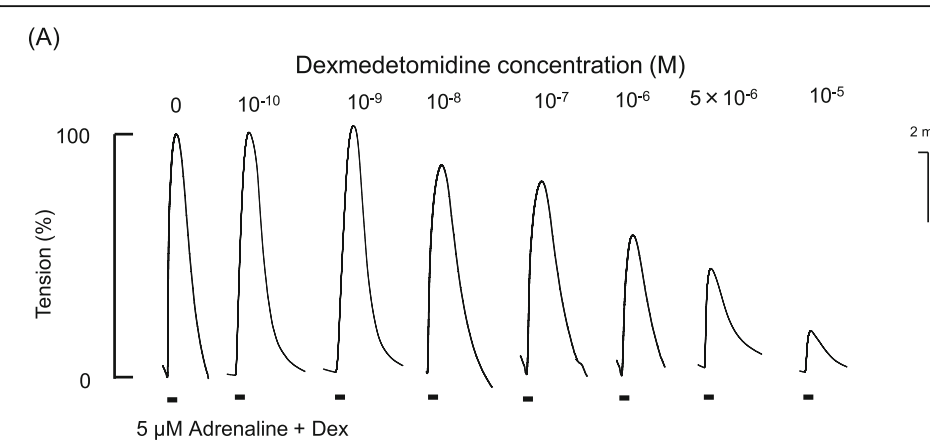

(C)

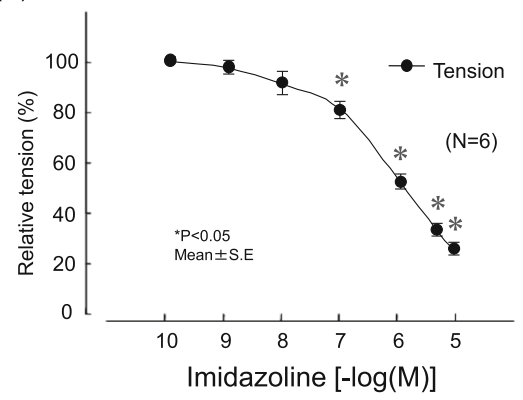

(D)

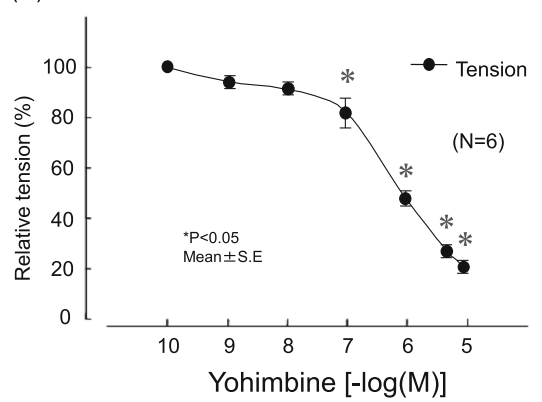

(B)

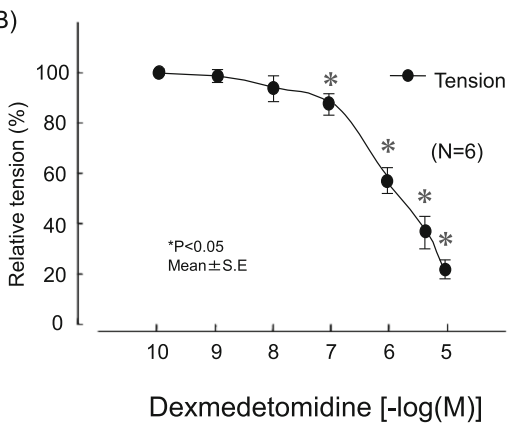

(E)

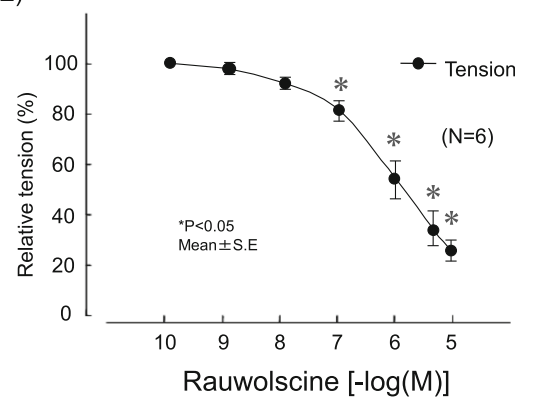

Fig. 5 Effects of dexmedetomidine (Dex), imidazoline, yohimbine, and rauwolscine on contraction tension induced with $5 \mu \mathrm{M}$ adrenaline. a Representative traces show the effects of Dex on tension. $\mathbf{b}-\mathbf{e}$ Analyzed data. Changes in contraction tension were normalized to $5 \mu \mathrm{M}$ adrenaline in each set and expressed as a relative value (in percents). The tensions were measured relative to the adrenaline baseline. Statistical analysis was performed with one-way analysis of variance followed by Dunnett's multiple comparison procedure. Each bar and accompanying line indicate the mean and SE of a group. There were six samples per group. ${ }^{*} P<0.05$, compared with $5 \mu \mathrm{M}$ adrenaline

with $\mathrm{Ca}^{2+}$-free $\mathrm{HBSS}$, induced a transient increase in contraction tension. The second and third caffeine doses, which were administered after fixing the $\mathrm{Ca}^{2+}$-induced $\mathrm{Ca}^{2+}$ release (CICR) channels in the open state with ryanodine, induced no appreciable changes in contraction tension. When $\mathrm{Ca}^{2+}$-containing adrenaline was administered in this state, the contraction tension slowly increased and then remained in a steady state (control). The $\mathrm{Ca}^{2+}$-containing adrenaline solution also containing Dex administered under the same conditions as the control induced changes in contraction tension similar to those in the control, although the maximum value was significantly lower (Fig. 6).

\section{Effects of Dex on adrenaline-, caffeine- and histamine- induced contraction tension in the absence of extracellular $\mathrm{Ca}^{2+}$}

When $\mathrm{Ca}^{2+}$ was present in the intracellular reservoir but absent in the extracellular fluid, contraction tension transiently increased with administration of adrenaline, caffeine, and histamine and then rapidly decreased (control). Dex-containing adrenaline, caffeine, and histamine administered under the same conditions as the control induced changes in contraction tension similar to those in the control. Dex-containing adrenaline and histamine produced significantly lower maximum values, whereas
Dex-containing caffeine had no effect on contraction tension (Fig. 7).

\section{Discussion}

This study produced two major findings. First, in porcine pulmonary arterial vascular smooth muscle, Dex increased contraction tension that had been induced by depolarization stimulation with high-concentration $\mathrm{KCl}$ and reduced the increases in contraction tension induced by adrenaline receptor stimulation. These effects were concentration-dependent in both cases. Second, Dex suppressed receptor-activated $\mathrm{Ca}^{2+}$ channels (RACCs), which allow extracellular $\mathrm{Ca}^{2+}$ into the cells, and phosphatidylinositol-1,4,5-triphosphate ( $\left.\mathrm{IP}_{3}\right)$ induced $\mathrm{Ca}^{2+}$ release (IICR), which releases intracellular $\mathrm{Ca}^{2+}$. Dex did not suppress CICR.

In porcine pulmonary arterial vascular smooth muscle, Dex enhanced the contraction induced by high-concentration $\mathrm{KCl}$ stimulation (Figs. 2 and 3). Conversely, the Dex-induced enhancement of contraction induced by high-concentration $\mathrm{KCl}$ was completely suppressed by yohimbine and rauwolscine ( $\alpha_{2}$-receptor antagonists) but not by prazosin ( $\alpha_{1}$-receptor antagonist) (Fig. 4). These results suggest that Dex's enhancing effect on vascular smooth muscle contraction induced by high- 


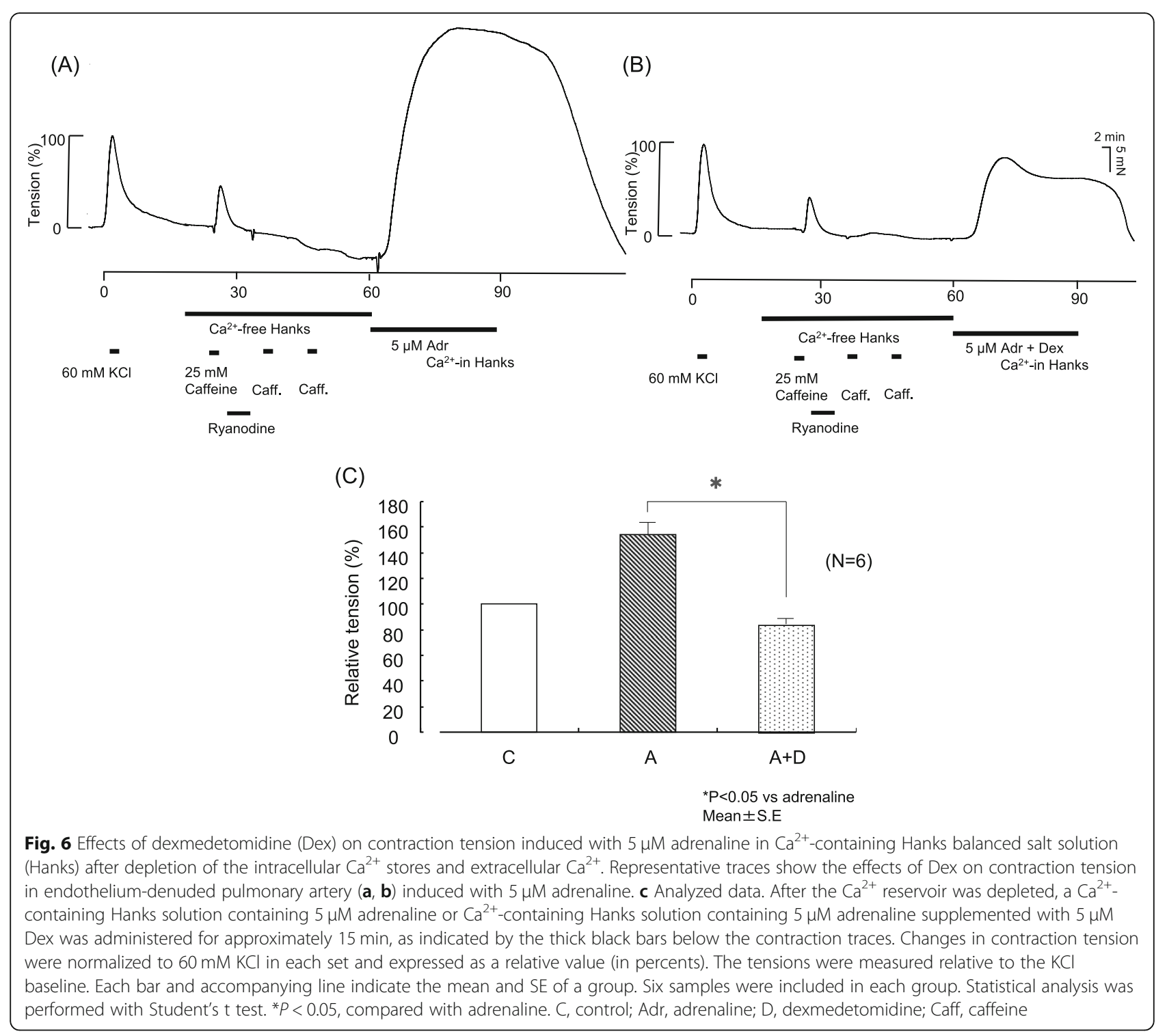

concentration $\mathrm{KCl}$ depolarization is mediated by an $\alpha_{2}$-receptor mechanism.

A study of endothelium-denuded human gastroepiploic arteries showed that the enhancement of highconcentration $\mathrm{KCl}$-induced vascular smooth muscle contraction induced by adding Dex was completely antagonized by the $\alpha_{2}$-receptor antagonists yohimbine and rauwolscine, leading the authors to conclude that the enhancing effect of Dex is mediated by $\alpha_{2}$ receptors [11]. Another study, on the human forearm, showed that the vasoconstriction effect of Dex after administration of a $\beta$ - or $\alpha_{2}$-receptor antagonist was completely antagonized by the $\alpha_{2}$-receptor antagonist yohimbine [12].

In general, high-concentration $\mathrm{KCl}$-induced contraction of vascular smooth muscle is mediated by increased
$\mathrm{Ca}^{2+}$ brought about by an influx of extracellular $\mathrm{Ca}^{2+}$ via voltage-dependent $\mathrm{Ca}^{2+}$ channels (VDCCs). These channels open in response to cell membrane depolarization, resulting in intracellular CICR via ryanodine receptors on endoplasmic reticulum (ER) [13]. Dex-induced increases in high-concentration $\mathrm{KCl}$-induced contraction tension may promote VDCC-mediated influx of extracellular $\mathrm{Ca}^{2+}$ and/or CICR. Stimulation with caffeine activates ryanodine receptors on the ER and promotes CICR to increase $\mathrm{Ca}^{2+}$, resulting in contraction. In the present experiment, Dex had no effect on caffeine-induced increases during contraction tension in the $\mathrm{Ca}^{2+}$ free HBBS solution (Fig. 7). Therefore, the mechanism by which Dex increases depolarization-induced contraction of the pulmonary arterial vascular smooth muscle is not facilitation of CICR from the $\mathrm{Ca}^{2+}$ reservoir. Rather, 


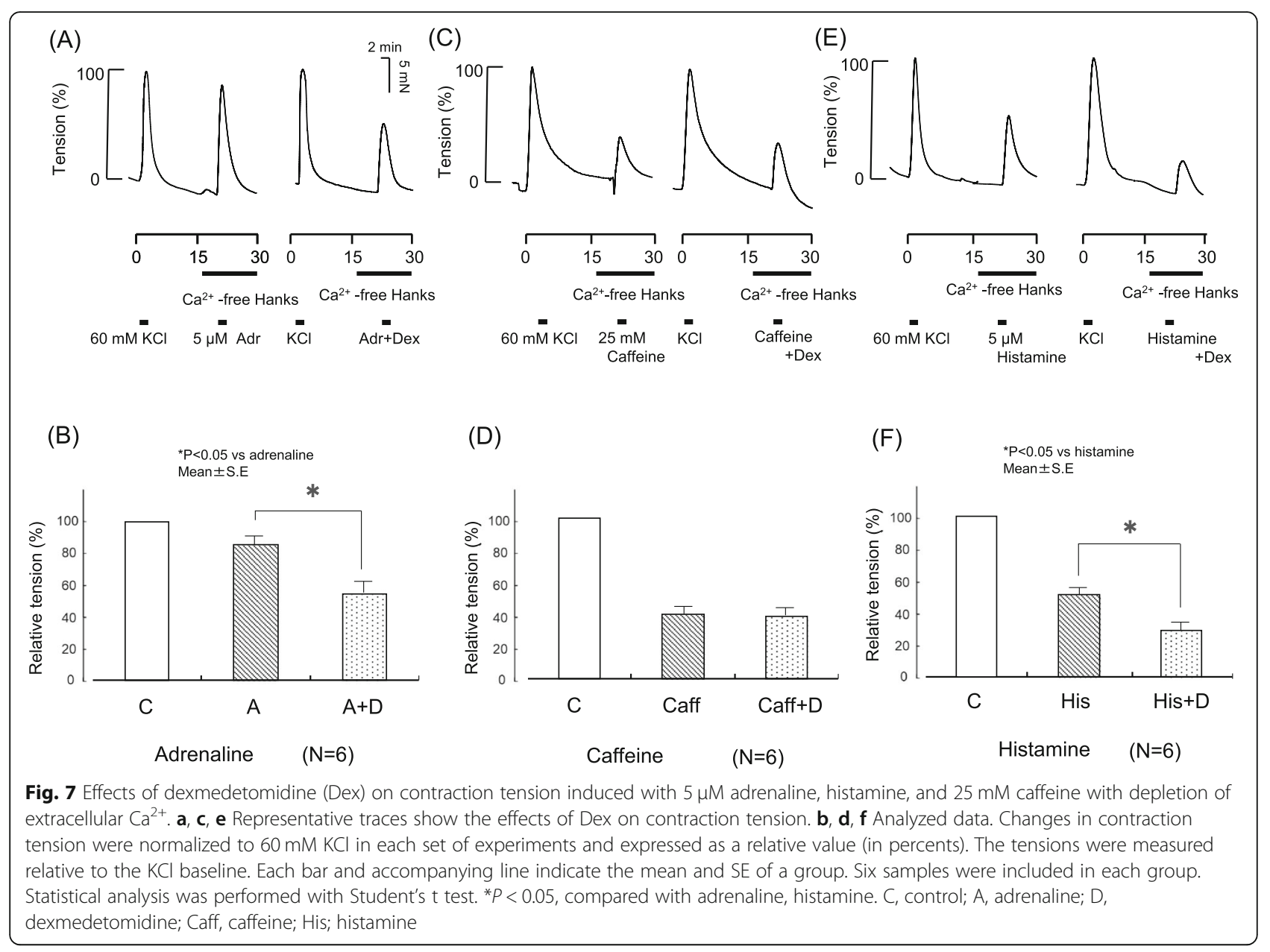

the increase is likely to result from facilitated influx of extracellular $\mathrm{Ca}^{2+}$ via VDCCs. $\alpha_{2}$-Receptor-induced contraction of human subcutaneous resistance arteries depends, at least in part, on $\mathrm{Ca}^{2+}$ influx via L-type VDCCs [14]. $\alpha_{2}$-Receptor stimulants directly promote VDCCs by a mechanism that depends on a $G$ protein associated with protein kinase $C$ activation [15]. It has also been reported that $\alpha_{2}$-receptor stimulation in rat saphenous vein vascular smooth muscle results from depolarization of the cell membrane, which indirectly enhances $\mathrm{Ca}^{2+}$-dependent contraction and $\mathrm{Ca}^{2+}$ sensitivity through VDCC activation [16]. Because Dex has an imidazole group, it is believed to act not only on the $\alpha_{2}$ receptor but also on imidazoline receptors [17]. We therefore administered imidazoline, which is an imidazoline-receptor stimulant, and compared its effects with those of Dex. Imidazoline also increases contractions resulting from depolarization with high-concentration $\mathrm{KCl}$ (Figs. 2, 3).

The $\alpha_{2}$-receptor stimulant Dex, imidazoline-receptor stimulant imidazoline, and $\alpha_{2}$-receptor antagonists yohimbine and rauwolscine produced concentration-dependent decreases in contraction induced by the $\alpha_{1} \alpha_{2}$-receptor stimulant adrenaline (Fig. 5). Dex and imidazoline suppressed contraction resulting from adrenaline, suggesting that receptor stimulants containing an imidazoline group inhibit receptor stimulation involving both $\alpha_{1}$ and $\alpha_{2}$. In the present study, adrenaline-induced contraction was suppressed by the $\alpha_{2}$-receptor stimulant Dex, the imidazoline-receptor stimulant imidazoline, and the $\alpha_{2}$-receptor antagonists yohimbine and rauwolscine. These findings suggest that the effect of Dex on adrenaline-induced contraction is attributable to its $\alpha_{2}$-receptor-blocking action.

Dex inhibited RACC and IICR but not CICR. Cell membrane $\mathrm{Ca}^{2+}$ channels regulated by receptor stimulation include RACCs, which are receptors that have a channel function coupled with receptor stimulants and that mediate the influx of extracellular $\mathrm{Ca}^{2+}$. Receptor stimulants activate phospholipase $\mathrm{C}$ by activating $\mathrm{G}$ protein-coupled receptors on the cell membrane, resulting in the production of $\mathrm{IP}_{3}$ from phosphatidylinositol, a lipid component of the cell membrane. $\mathrm{IP}_{3}$ production 
leads to activation of IICR from the intracellular reservoir [18]. Influx of extracellular $\mathrm{Ca}^{2+}$ and $\mathrm{IP}_{3}$ activate ryanodine receptors on the ER, causing CICR from the $\mathrm{Ca}^{2+}$ reservoir. Both $\mathrm{IP}_{3}$ and ryanodine receptors, which are present on the ER, play an important role in the regulation of $\mathrm{Ca}^{2+}$ release [19]. Vascular smooth muscle contraction is regulated by changes in the $\mathrm{Ca}^{2+}$ sensitivity of contraction proteins through phospholipase $\mathrm{C}$ activation by receptor stimulation [20].

The present study showed that Dex reduced the increases in contraction tension induced by the receptor stimulant adrenaline, suggesting that it suppressed RACC-mediated influx of extracellular $\mathrm{Ca}^{2+}$, IICR, and/ or CICR (Fig. 5). Dex's suppression of adrenaline-induced increases in contraction tension after depletion of $\mathrm{Ca}^{2+}$ suggest that Dex reduces the RACC-mediated influx of extracellular $\mathrm{Ca}^{2+}$ (Fig. 6). Dex's suppression of adrenaline-induced increases in contraction tension in the absence of extracellular $\mathrm{Ca}^{2+}$ suggest that Dex suppresses IICR and/or CICR (Fig. 7). In the absence of extracellular $\mathrm{Ca}^{2+}$, Dex did not affect caffeine-induced increases in contraction tension (Fig. 7). Caffeine stimulation activates ryanodine receptors on the ER and promotes CICR to induce contraction [13]. This mechanism suggests that Dex suppresses IICR because it did not suppress CICR.

We also conducted experiments with histamine to confirm that Dex suppresses IICR. Receptor stimulation by histamine is coupled with phospholipase $\mathrm{C}$ via $\mathrm{Gq}$, a $\mathrm{G}$ protein-mediated, seven-transmembrane receptor. $\mathrm{Ca}^{2+}$ is recruited via $\mathrm{IP}_{3}$ as a second messenger. Contraction then occurs via diacylglycerol-mediated activation of protein kinase $C$ [21]. Thus, histamine is believed to act specifically on IICR [22].

Our previous study showed that receptor stimulation in the absence of $\mathrm{Ca}^{2+}$ in the extracellular fluid, and following depletion of the $\mathrm{Ca}^{2+}$ reservoir with caffeine and ryanodine, did not cause any changes in contraction tension [18]. This finding indicates that $\mathrm{IP}_{3}$ receptor stimulation results in no $\mathrm{Ca}^{2+}$ release from the $\mathrm{Ca}^{2+}$ reservoir when ryanodine receptors are fixed in the open state. The experiment showed that the histamine-induced increase in contraction tension was reduced in the absence of extracellular $\mathrm{Ca}^{2+}$, suggesting that Dex suppresses IICR.

When the 6-month-old pig whose tissues were used in the present experiments was euthanized, the major stress of the animal could have produced depletion of the $\mathrm{Ca}^{2+}$ reservoir. All pigs at that location are euthanized routinely with an electrical method. Hence, the euthanasia protocol did not introduce bias in the results.

The selection of Dex at a concentration of $5 \mu \mathrm{M}$ was based on the following data. Figure 2 shows that Dex increased the $60 \mathrm{mM} \mathrm{KCl}$-induced contraction tension, with the observed increases reaching significance at a Dex concentration of $\geq 1 \mu \mathrm{M}$ and with the increases reaching $\geq 20 \%$ at Dex concentrations of $\geq 5 \mu \mathrm{M}$. We accepted that the $50 \%$ inhibitory concentration of Dex was $2.083 \mu \mathrm{M}$ based on a dose-dependent curve (Fig. 5). We therefore needed 60-70\% maximum inhibition. Hence, we decided to use $5 \mu \mathrm{M}$ as the cutoff. Dex at high doses activates the $\alpha_{2} \beta$-receptors distributed in vascular smooth muscle, causing hypertension resulting from contraction of vascular smooth muscle. At low doses, Dex causes hypotension resulting from vasodilation and bradycardia due to parasympathetic dominance [19]. The blood concentration of Dex required to maintain a sedative effect in humans is reported to be similar, at $1.0 \times 10^{-9} \mathrm{~g} / \mathrm{mL}$ (i.e., $4.0 \times 10^{-9} \mathrm{~mol} / \mathrm{L}$ ) [23, 24]. The present results show that Dex had no effect on vasoconstrictor responses in porcine pulmonary arteries when applied in clinically effective concentrations. The previously reported systemic effects of Dex observed in the clinical setting, including decreased blood pressure, may not be the result of direct actions on vascular smooth muscle but could be due to decreased central and peripheral sympathetic nervous system activity [11]. One clinical report also suggested that, at large doses $\left(>10^{-8}\right.$ $\mathrm{mol} / \mathrm{L}$ ), Dex increases peripheral vascular resistance, leading to increased blood pressure [13]. Although the mechanism of blood pressure increase is unclear, it cannot be ruled out that the vasoconstrictor effects of Dex shown in this study (i.e., those mediated by VDCC activation or in case of accidental intravenous administration) may be relevant in such cases.

\section{Conclusions}

To elucidate the effects and mechanism of action of Dex on vascular smooth muscle of the pulmonary artery, we measured isometric contraction tension in that artery. Dex increased the contraction tension resulting from depolarization stimulation by high-concentration $\mathrm{KCl}$. The enhancement of high-concentration $\mathrm{KCl}$-induced contraction when adding Dex was completely antagonized by the $\alpha_{2}$-receptor antagonists yohimbine and rauwolscine. Thus, Dex's enhancing effect was mediated by $\alpha_{2}$-receptors. Adrenaline-induced contraction was suppressed by the $\alpha_{2}$-receptor stimulants Dex and imidazoline and the $\alpha_{2}$-receptor antagonists yohimbine and rauwolscine, suggesting that the effect of Dex on adrenaline-induced contraction is attributable to its $\alpha_{2}$-receptor-blocking action. Dex suppressed the adrenalineinduced increases in contraction tension after depletion of $\mathrm{Ca}^{2+}$ reservoir. In the absence of extracellular $\mathrm{Ca}^{2+}$, Dex suppressed the adrenaline- and histamine-induced increases but did not affect caffeine-induced increases in contraction tension. Also, Dex inhibited RACC and IICR but not CICR. 


\section{Abbreviations}

CICR: $\mathrm{Ca}^{2+}$-induced $\mathrm{Ca}^{2+}$ release; Dex: Dexmedetomidine; ER: Endoplasmic reticulum; HBSS: Hank's balanced salt solution; IICR: IP ${ }_{3}$-induced $\mathrm{Ca}^{2+}$ release; $\mathrm{IP}_{3}$ : Phosphatidylinositol-1,4,5-triphosphate; RACC: Receptor-activated $\mathrm{Ca}^{2+}$ channel; VDCC: Voltage-dependent $\mathrm{Ca}^{2+}$ channel

\section{Acknowledgments}

We thank Nancy Schatken BS, MT (ASCP), from Liwen Bianji, Edanz Group China (www.liwenbianji.cn/ac), for editing the English text of a draft of this manuscript.

\section{Authors' details}

Division of Dental Anesthesiology, Department of Reconstructive Oral and Maxillofacial Surgery, School of Dentistry, Iwate Medical University, 1-3-27 Chuo-dori, Morioka, Iwate 020-8505, Japan.

\section{Authors' contributions}

MC contributed to data collection, data analysis, and manuscript preparation; approved the final manuscript; and attests to the integrity of the original data and the analysis reported in this manuscript. KS contributed to study design, data collection, data analysis, and manuscript preparation; approved the final manuscript, and attests to the integrity of the original data and the analysis reported in this manuscript. Both authors read and approved the final manuscript.

\section{Funding}

There was no funding for this manuscript.

\section{Availability of data and materials}

The datasets used and/or analyzed during the current study are available from the corresponding author on reasonable request.

\section{Ethics approval and consent to participate}

This study was approved by the Institutional Review Committee on the Ethics of Animal Experiments of Iwate Medical University. All experiments were conducted in accordance with the Institutional Animal Care and Use Committee guidelines (Ethical number 26-010).

\section{Consent for publication}

Not applicable.

\section{Competing interests}

The authors declare that they have no competing interests.

\section{Received: 3 April 2019 Accepted: 26 August 2019}

\section{Published online: 12 September 2019}

\section{References}

1. Klimscha W, Chiari A, Krafft P, Plattner O, Taslimi R, Mayer N, Weinstabl C, Schneider B, Zimpfer M. Hemodynamic and analgesic effects of clonidine added repetitively to continuous epidural and spinal blocks. Anesth Analg. 1995:80:322-7.

2. Memiş D, Turan A, Karamanlioğlu B, Pamukçu Z, Kurt I. Adding dexmedetomidine to lidocaine for intravenous regional anesthesia. Anesth Analg. 2004;98:835-40

3. Calasans-Maia JA, Zapata-Sudo G, Sudo RT. Dexmedetomidine prolongs spinal anaesthesia induced by levobupivacaine $0.5 \%$ in guinea-pigs. J Pharm Pharmacol. 2005:57:1415-20.

4. Yoshitomi T, Kohjitani A, Maeda S, Higuchi H, Shimada M, Miyawaki T. Dexmedetomidine enhances the local anesthetic action of lidocaine via an alpha-2A adrenoceptor. Anesth Analg. 2008;107:96-101.

5. Yabuki A, Higuchi H, Yoshitomi T, Tomoyasu Y, Ishii-Maruhama M, Maeda S, Miyawaki T. Locally injected dexmedetomidine induces vasoconstriction via peripheral a-2A adrenoceptor subtype in guinea pigs. Reg Anesth Pain Med. 2014:39:133-6.

6. Sukegawa S, Higuchi H, Inoue M, Nagatsuka H, Maeda S, Miyawaki T. Locally injected dexmedetomidine inhibits carrageenin-induced inflammatory responses in the injected region. Anesth Analg. 2014;118:473-80.

7. Maki J, Hirano M, Hoka S, Kanaide H, Hirano K. Thrombin activation of proteinase-activated receptor 1 potentiates the mypfilament $\mathrm{Ca}^{2+}$ sensitivity and induce vasoconstriction in porcine pulmonary arteries. Br J Pharmacol. 2010:159:919-27.

8. Satoh K, Kamada S, Kumagai M, Sato M, Kuji A, Joh S. Effect of lidocaine on swine lingual and pulmonary arteries. J Anesth. 2015;29:529-34. https://doi. org/10.1007/s00540-014-1965-9

9. Satoh K, Chikuda M, Ohashi A, Kumagai M, Sato M, Joh S. The effect of mepivacaine on swine lingual, pulmonary and coronary arteries. BMC Anesthesiol. 2015;15:101. https://doi.org/10.1186/s12871-015-0085-x.

10. Heck DA, Bylund DB. Differential down-regulation of alpha-2 adrenergic receptor subtypes. Life Sci. 1998;62(17-18):1467-72.

11. Hamasaki J, Tsuneyoshi I, Katai R, Hidaka T, Boyle WA, Kanmura Y. Dual alpha (2)-adrenergic agonist and alpha (1)-adrenergic antagonist actions of dexmedetomidine on human isolated endothelium-denuded gastroepiploic arteries. Anesth Analg. 2002;94:1434-40.

12. Masuki S, Dinenno FA, Joyner MJ, Eisenach JH. Selective alpha2-adrenergic properties of dexmedetomidine over clonidine in the human forearm. J Appl Physiol (1985). 2005;99:587-92.

13. lino M. Calcium release mechanisms in smooth muscle. Jpn J Pharmacol. 1990;54:345-54.

14. Nielsen H, Mortensen FV, Pilegaard HK, Hasenkam JM, Mulvany MJ. Calcium utilization coupled to stimulation of postjunctional alpha-1 and alpha-2 adrenoceptors in isolated human resistance arteries. J Pharmacol Exp Ther. 1992;260:637-43.

15. Lepretre N, Mironneau J, Morel JL. Both [alpha]1A- and [alpha]2Aadrenoceptor subtypes stimulate voltage-operated L-type calcium channels in rat portal vein myocytes. J Biol Chem. 1994;269:29546-52.

16. Cheung DW. An electrophysiological study of [alpha]-adrenoceptor mediated excitation-coupling in smooth muscle cells of the rat saphenous vein. Br J Pharmacol. 1985:84:265-71.

17. Parkinson NA, Hughes AD. The mechanism of action of [alpha]2adrenoceptors in human isolated subcutaneous resistance arteries. $\mathrm{Br}$ J Pharmacol. 1995;115:1463-8.

18. Satoh $\mathrm{K}$. The contractile mechanism of adrenaline on vascular smooth muscle in porcine tongue (in Japanese with English abstract). Nihon Sikamasui Gakkai Zassi (J Jpn Dent Soc Anesthesiol). 1997:25:398-409.

19. Ebert TJ, Hall JE, Barney JA, Uhrich TD, Colinco MD. The effects of increasing plasma concentrations of dexmedetomidine in humans. Anesthesiology. 2000;93:382-94.

20. Talke PO, Caldwell JE, Richardson CA, Kirkegaard-Nielsen H, Stafford M. The effects of dexmedetomidine on neuromuscular blockade in human volunteers. Anesth Analg. 1999;88:633-9.

21. Jeong JH, Yun MC, Shin CY, Lee TS, Song HJ, Sohn UD. Signaling via histamine receptors in cat duodenal smooth muscle cells. Mol Cells. 2003; 16:180-6.

22. Mauban JR, Wilkinson K, Schach C, Yuan JX. Histamine-mediated increases in cytosolic $\left[\mathrm{Ca}^{2+}\right]$ involve different mechanisms in human pulmonary artery smooth muscle and endothelial cells. Am J Physiol Cell Physiol. 2006;290: C325-36

23. Jalonen J, Hynynen M, Kuitunen A, Heikkilä H, Perttilä J, Salmenperä M, Valtonen M, Aantaa R, Kallio A. Dexmedetomidine as an anesthetic adjunct in coronary artery bypass grafting. Anesthesiology. 1997;86:331-45.

24. Talke P, Chen R, Thomas B, Aggarwall A, Gottlieb A, Thorborg P, Heard S, Cheung A, Son SL, Kallio A. The hemodynamic and adrenergic effects of perioperative dexmedetomidine infusion after vascular surgery. Anesth Analg. 2000;90:834-9.

\section{Publisher's Note}

Springer Nature remains neutral with regard to jurisdictional claims in published maps and institutional affiliations. 